\title{
Synthesis, X-Ray Structure, Hirshfeld Surface Analysis, DFT Calculations, and Molecular Docking Studies of Nickel(II) Complex with Thiosemicarbazone Derivative
}

\author{
Uwaisulqarni M. Osman $\left(\mathbb{D},{ }^{1,2}\right.$ Sharmili Silvarajoo, ${ }^{1}$ Muhamad Fairus Noor Hassim $\left(\mathbb{D},{ }^{3}\right.$ \\ Suhana Arshad $\left(\mathbb{1},{ }^{4}\right.$ Ainizatul Husna Anizaim, ${ }^{4}$ and Fazira Ilyana Abdul Razak $\mathbb{1}^{5}$ \\ ${ }^{1}$ Faculty of Science and Marine Environment, Universiti Malaysia Terengganu, 21030 Kuala Nerus, Terengganu, Malaysia \\ ${ }^{2}$ Advanced Nano Materials Research Group (ANOMA), Ionic State Analysis (ISA) Laboratory, Universiti Malaysia Terengganu, \\ 21030 Kuala Nerus, Terengganu, Malaysia \\ ${ }^{3}$ Biological Security and Sustainability (BIOSES) Research Group, Faculty of Science and Marine Environment, \\ Universiti Malaysia Terengganu, 21030 Kuala Nerus, Terengganu, Malaysia \\ ${ }^{4}$ X-Ray Crystallography Unit, School of Physics, Universiti Sains Malaysia, 11800 USM, Pulau Pinang, Malaysia \\ ${ }^{5}$ Faculty of Science, Universiti Teknologi Malaysia, 81310 Skudai, Johor Bahru, Malaysia
}

Correspondence should be addressed to Uwaisulqarni M. Osman; uwais@umt.edu.my

Received 3 February 2021; Revised 4 May 2021; Accepted 17 May 2021; Published 27 May 2021

Academic Editor: Massimiliano F. Peana

Copyright () 2021 Uwaisulqarni M. Osman et al. This is an open access article distributed under the Creative Commons Attribution License, which permits unrestricted use, distribution, and reproduction in any medium, provided the original work is properly cited.

\begin{abstract}
This article presents both experimental and computational study of a new Ni(II) complex, namely, bis $\{2$-(2-trifluoromethylbenzylidene)hydrazine-1-carbothioamido- $\kappa^{2} \mathrm{~N}^{2}$, S\}nickel(II) (abbreviate as $\mathrm{NiL}_{2}$ ). The complex was synthesized and well characterized using various spectroscopic methods. The single X-ray crystallographic study revealed a distorted square planar geometry around $\mathrm{Ni}$ (II) metal ion centre in which the angles deviated from ideal $90^{\circ}$ with a maximum value of $6.57^{\circ}$ occupied by nitrogen and sulphur donor atoms. The theoretical bond lengths and angles for the $\mathrm{NiL}_{2}$ complex were obtained by using the B3LYP level of density function theory (DFT) with LANL2DZ/6-311G $(d, p)$ basis sets. These results showed very good agreement with the experimental X-ray values. The electrophilicity index $(\omega=50.233 \mathrm{eV})$ shows that the $\mathrm{NiL}_{2}$ complex is a very strong electrophile. In addition, strong $\mathrm{F} \cdots \mathrm{H} / \mathrm{H} \cdots \mathrm{F}$ interactions with $28.5 \%$ of the total Hirshfeld surface analyses in $\mathrm{NiL}_{2}$ were obtained indicating that the complex could bind with protein effectively. Furthermore, the new $\mathrm{NiL}_{2}$ complex was docked with plasma retinol-binding protein 4 (RBP4) (PDB id: 5NU7), which implied that the $\mathrm{NiL}_{2}$ complex bound to Tyrosine 133 and Aspartate 102 amino acids via $\mathrm{N}-\mathrm{H}$ intermolecular hydrogen bonds.
\end{abstract}

\section{Introduction}

Recent interest in the chemistry of thiosemicarbazone ligands arises mainly from the potential from both azomethine nitrogen and thiolate sulphur donor atoms with variance coordination modes of either monodentate [1], bidentate [2], or tridentate [3]. This variance can be performed by introducing different substituents in order to form a selection of mononuclear [4] and polynuclear [5] complexes.

The versatility of thiosemicarbazone derivatives and its metal complexes allows for the design and development of bioactive compounds, including anticancer [6], antioxidant [7], and antibacterial [8]. (E)-2-(1-(3-Bromophenyl)ethylidene)hydrazine-1-carbothioamide molecule shows high potential in behaving as antimalarial agents [9]. Due to these reasons, their structural details are considered useful for structure activity relationships (SAR) design for future applications.

In continuation of our research to develop coordination chemistry of thiosemicarbazones and their transition metal complexes $[10,11]$, a new $\mathrm{Ni}(\mathrm{II})$ complex, namely, bis $\{2$-(2-trifluoromethylbenzylidene)hydrazine1-carbothioamido- $\left.\kappa^{2} \mathrm{~N}^{2}, \mathrm{~S}\right\}$ nickel(II), $\mathrm{NiL}_{2}$ containing 
(trifluoromethyl)benzene, and thiosemicarbazone moieties have been synthesized, characterized, and computationally optimized using B3LYP level of density function theory (DFT) with LANL2DZ/6-311G $(d, p)$ basis sets. The experimental X-ray crystallographic structure of the $\mathrm{Ni}$ (II) complex also has been correlated with the corresponding structure optimized at DFT/ B3LYP/LANL2DZ/6-311G $(d, p)$ level. In addition, Hirshfeld surface analysis was also used to interpret intermolecular interactions in the $\mathrm{NiL}_{2}$ complex by visual representations whereas molecular docking was studied to know the receptor-amino acid interactions, to predict the important functional groups or atoms in the complex.

\section{Materials and Methods}

2.1. General Procedure. All the chemicals were purchased from Aldrich, R\&M, and HmbG and used without further purification. Elemental analysis was performed with a CHNS-O Flashea Siri 112 Analyzer. Magnetic measurements were carried out on a Johnson Matthey Mark I MSB magnetic susceptibility balance model MKIC using Gouy's method. The molar conductance of freshly prepared $1.0 \times 10^{-3} \mathrm{M}$ in DMSO solutions was measured for the $\mathrm{NiL}_{2}$ complex using Jenway 4320 conductivity meter. Electronic spectra were recorded on Shimadzu UV-1800 UV spectrophotometer and the samples were prepared with $1.0 \times 10^{-5} \mathrm{M}$ in DMSO solutions.

2.2. Synthesis of $\mathrm{NiL}_{2}$. A solution of $20 \mathrm{~mL}$ hot ethanol of nickel(II) acetate tetrahydrate, $\mathrm{Ni}(\mathrm{Ac})_{2} .4 \mathrm{H}_{2} \mathrm{O} \quad(0.07 \mathrm{~g}$, $0.3 \mathrm{mmol}$ ) was added to $30 \mathrm{~mL}$ hot solution of 1-(2-trifluoromethylbenzylidene)thiosemicarbazide $\quad(0.33 \mathrm{~g}$, $0.6 \mathrm{mmol}$ ) in a ratio of $1: 2$, respectively. The mixture was heated under reflux for 3 hours. The brown precipitate formed was filtered, washed with cold ethanol, and kept in a desiccator. Suitable single crystals of the $\mathrm{NiL}_{2}$ complex were obtained from a methanol: DMF mixture solution through the vapor diffusion method. The chemical equation for the reaction is shown in Scheme 1. Yield 68.28\%. Melting point $246.72^{\circ} \mathrm{C}$. Analysis calculated for $\mathrm{C}_{18} \mathrm{H}_{16} \mathrm{~N}_{6} \mathrm{~S}_{2} \mathrm{~F}_{2} \mathrm{Ni}$ : C, 39.88; H, 2.97; N, 15.50; S, 11.83. Found: C, 40.66; H, 3.29; N, 16.14; $\mathrm{S}, 13.61 \%$. $\lambda_{\max }(\mathrm{nm}): 269 \mathrm{n} \longrightarrow \pi^{*}, 328$ (LMCT transition), $\sim 450\left({ }^{1} \mathrm{~A}_{1} \mathrm{~g} \longrightarrow{ }^{1} \mathrm{~A}_{2} \mathrm{~g}\right)$. Molar conductance: $1.37 \Omega^{-1} \mathrm{~cm}^{2}$ $\mathrm{mol}^{-1} \cdot \mu_{\mathrm{eff}}$ (B.M.): 0.0 .

2.3. X-Ray Diffraction Studies. A single-crystal X-ray diffraction (SCXRD) study of $\mathrm{NiL}_{2}$ was performed on Bruker SMART Apex II Duo CCD area-detector diffractometers using MoK $\alpha$ radiation $(\lambda=0.71073 \AA)$. The data collection was performed by APEX2 software [12], whereas the cell refinement and data reduction were performed by SAINT software [12]. The crystallographic structure was solved by Direct Method using SHELXTL [13] and further refined by full-matrix least squares technique on $\mathrm{F}^{2}$ using anisotropic displacement parameters by SHELXTL [13]. Absorption correction was applied to the final crystal data using the SADABS software [12]. All geometrical calculations were carried out using the program
PLATON [14]. The molecular graphics were drawn using SHELXTL [13]. All the hydrogen atoms were positioned geometrically $(\mathrm{C}-\mathrm{H}=0.93 \AA)$ and refined using riding model $U_{\text {iso }}(\mathrm{H})=1.2 U_{\text {eq }}(\mathrm{C})$ which means the isotropic displacement parameters are set to $1.2(\mathrm{C})$ times the equivalent isotropic $U$ values of the parent carbon atoms. Additionally, the $\mathrm{N}$-bound $\mathrm{H}$ atoms were located in a difference Fourier map and freely refined $(\mathrm{N}-\mathrm{H}=0.86 \AA)$. Selected crystal structure parameters are listed in Table 1.

2.4. Computational Details. This study reports computational studies on $\mathrm{NiL}_{2}$ complex. All calculations were performed by Gaussian 16 using high performance computer (HPC) provided by CICT, UTM along with Gauss View 6.0 for visualizations. The geometries were fully optimized without any constraint on every bond length, bond angle, and dihedral angle. Geometry optimizations were conducted using the unrestricted DFT method at the level of B3LYP/ LANL2DZ/6-311G $(d, p)$ (B3LYP/GENECP) with the keyword "OPT". The highest occupied molecular orbital (HOMO) and the lowest unoccupied molecular orbital (LUMO) were also performed under the same basic set. The reactivity descriptors that include energy gap $\left(\Delta E_{\text {gap }}\right)$, hardness $(\eta)$, softness $(S)$, global electronegativity $(\chi)$, and electrophilicity $(\omega)$ have also been computed by the same approach as from our previous work [15].

2.5. Molecular Docking. The crystal structure of plasma retinol-binding protein (RBP4) was obtained from the RSCB protein database (PDB ID:5NU7). The 5NU7 structure was selected due to high $3 \mathrm{D}$ crystal structure resolution at $1.5 \AA$. The active binding site of RBP4 was predicted using 3DLigandSite (http://www.sbg.bio.ic.ac.uk/ 3dligandsite/) [16]. Docking analysis between $\mathrm{NiL}_{2}$ complex and $\mathrm{RBP} 4$ was using UCSF Chimera version 1.14 [17], AutoDock Vina [18], and LigPlot + v.1.4 [19]. Methodically, AutoDock Vina used the Broyden-Fletcher-Goldfarb-Shanno algorithm for molecular docking. The docking coordinate (grid box) were determined based on the result from 3DLigandSite, presence of pocket structure, and location of retinol in the RBP4 crystal structure.

\section{Results and Discussion}

Bis $\{2$-(2-trifluoromethylbenzylidene)hydrazine-1-carbothioamido- $\kappa^{2} \mathrm{~N}^{2}$, S\}nickel(II), $\mathrm{NiL}_{2}$ complex, was synthesized according to our reported procedures in [10], however with different reactants. Selected experimental and theoretical geometric parameters optimized of $\mathrm{NiL}_{2}$ complex structure are shown in Table 2. The molecular structure of the $\mathrm{NiL}_{2}$ complex obtained empirically was compared with theoretical calculation via DFT (Figure 1). Percentage of deviation between bond lengths and bond angles for $\mathrm{NiL}_{2}$ complex was calculated using equation (1). From Table 2, the average deviation percentage for both bond length and bond angles is a low value (1.94\% and $1.14 \%)$ indicating that experimental and calculation work is in good agreement. This is further proven by the statistical correlation graph that 


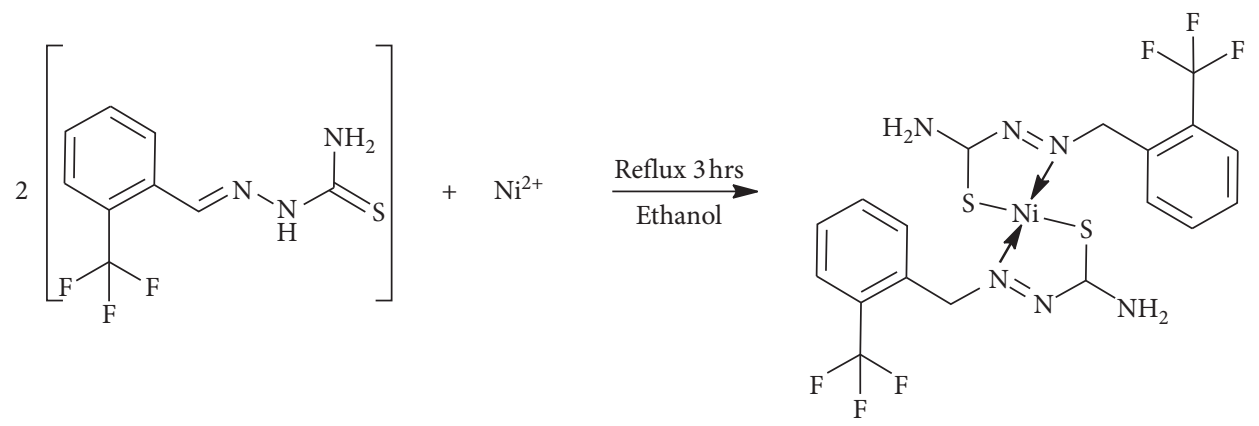

Scheme 1: Synthesis of $\mathrm{NiL}_{2}$ complex.

shows $R^{2}$ values of 0.99849 for bond length (Figure S1) and 0.99384 for bond angle (Figure S2). However, there is a slight difference in values from experimental crystallographic data which might be due to the theoretical results obtained for isolated complex in the gaseous phase, whereas the experimental results obtained for both intra- and interlinked complexes in the solid phase similar to the previous report [20]:

$$
\text { Percentage deviation }=\frac{\text { calculated value }- \text { experimental value }}{\text { experimental value }} \times 100 \%
$$

3.1. Molecular Structure Studies. X-ray crystal study of structure Bis\{2-(2-trifluoromethylbenzylidene)hydrazine-1carbothioamido- $\kappa^{2} \mathrm{~N}^{2}, \quad$ S\}nickel(II), $\left(\mathrm{NiL}_{2}\right)$ complex, $\mathrm{C}_{18} \mathrm{H}_{16} \mathrm{~F}_{6} \mathrm{~N}_{6} \mathrm{~S}_{2} \mathrm{Ni}$ with molecular weight $M=553.20 \mathrm{gmol}^{-1}$, showed the $\mathrm{NiL}_{2}$ complex crystallized in the orthorhombic system with a space group of $I b a 2$. The unit cell dimensions are $a=16.889(3) \AA, \quad b=15.777(3) \AA, \quad c=15.777 \AA$, and $\alpha=\beta=\gamma=90^{\circ}$. Important bond lengths and bond angles are given in Table 2. Figure 2 shows the molecular structure and atom numbering of the $\mathrm{NiL}_{2}$ complex, with thermal ellipsoids drawn at the $50 \%$ probability level.

The $\mathrm{NiL}_{2}$ complex is a bis-chelate complex of $\mathrm{Ni}(\mathrm{II})$ with two L ligands acting as bidentate chelate units (Figure 2). The distortion from square planar geometry is mainly due to the S1-Ni1-N1, S2-Ni1-N1, S2-Ni1-N4, and S1-Ni-N4 bond angles of 86.70(10), 96.57(10), 84.96(9), and $94.56(10)^{\circ}$, respectively, which differs from the ideal $90^{\circ}$ by a maximum value of $6.57^{\circ}$. Two ligand units, placed a bit curved to each other with twisted angles between the planes of the two coordinated ligands, are $25.03(14)^{\circ}$ with maximum r.m.s deviation of 0.159(3) $\mathrm{A}^{\circ}$ for $\mathrm{N} 4$ atom.

The pattern of bond length within the previous 1-(2-trifluoromethylbenzylidene)thiosemicarbazide ligand reported in [21] clearly indicates that the molecule is present in the thioamide form with both $\mathrm{C}-\mathrm{N}$ and $\mathrm{C}=\mathrm{S}$ bonds length of $1.343(6) \AA$ and 1.699 (4) $\AA$, respectively, consistently with the location of the $\mathrm{H}$ atom bonded to N2 atom. However, deprotonated for N2 atom in the present $\mathrm{NiL}_{2}$ complex was observed. Data of Table 2 show that, in the $\mathrm{Ni}(\mathrm{II})$ complex, there is a shortening and lengthening of both $\mathrm{C} 9-\mathrm{N} 2$ and $\mathrm{C} 9=\mathrm{S} 1$ bonds with $1.303(6) \AA$ and $1.717(4) \AA$, respectively. Thus, a tautomeric switch from thione to thiol form is postulate.

The molecular packing of $\mathrm{NiL}_{2}$ complex is mainly linked by three strong C8-H8A $\cdots$ S2, C8-H8A $\cdots$ F2, and C17-H17A $\cdots$ F6 intramolecular hydrogen bonds listed in Table 3, forming one pseudo-five and two pseudo-six membered graph set motifs. In the crystal structure, the $\mathrm{NiL}_{2}$ complex is interconnected

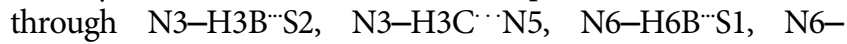
$\mathrm{H} 6 \mathrm{C}^{\prime} \mathrm{N} 2$, C5-H5A $\cdots$ F2, and C12-H12A $\cdots \mathrm{F} 3$ hydrogen bonds forming a three-dimensional architecture (Figure 3(a)). The molecules are further stabilized by weak $C g 1{ }^{\cdots} C g 3$ interactions (Cg1 and $C g 3$ are the centroids of Ni1/S1/C9/N2/N1 and C2/ C3/C4/C5/C6/C7, resp.) with the contact distance of 3.785(3) $\AA$ (symmetry code: $11-x, 1-y, z$ ), forming one-dimensional dimeric wave-like parallel to $b$-axis (Figure 3(b)).

3.2. UV-Vis Spectroscopy. The UV-Vis spectrum (Figure 4) of the $\mathrm{NiL}_{2}$ complex, bis\{2-(2-trifluoromethylbenzylidene) hydrazine-1-carbothioamido- $\kappa^{2} \mathrm{~N}^{2}, \quad$ S\}nickel(II), exhibits two bands at $\lambda_{\max }=269 \mathrm{~nm}$ and $328 \mathrm{~nm}$, which can be assigned to the $\pi \longrightarrow \pi$ transition of the conjugated phenyl ring and $n \longrightarrow \pi^{*}$ intraligand charge transfer (ILCT) transition of the $\mathrm{C}=\mathrm{S}$ and $\mathrm{CN}$ chromophore in ligand molecule [22]. In addition, a shoulder band which appeared at $\sim 450 \mathrm{~nm}$ in $\mathrm{NiL}_{2}$ complex can be assigned to ${ }^{1} \mathrm{~A}_{1} \mathrm{~g} \longrightarrow{ }^{1} \mathrm{~A}_{2} \mathrm{~g}$ transition. This band is well correlated with the previous study of the square planar $\mathrm{NiL}_{2}$ complex [22]. To further support, the magnetic moment of the $\mathrm{NiL}_{2}$ complex was shown of value 0 B.M, which is one of the main criteria for square planar geometry. [21] whereas low molar conductance with $1.37 \Omega^{-1} \mathrm{~cm}^{2} \mathrm{~mol}^{-1}$ showed the absence of acetate ion and nonelectrolytes in DMSO solution [23].

3.3. Frontier Molecular Orbitals Studies. The highest occupied molecular orbital (HOMO) and the lowest unoccupied molecular orbital (LUMO) are frequently studied in order to impart key information regarding the electron-donor and 
TABLE 1: Crystal data and structure refinement for $\mathrm{NiL}_{2}$.

\begin{tabular}{|c|c|}
\hline CCDC & 2023702 \\
\hline Empirical formula & $\mathrm{C}_{18} \mathrm{H}_{16} \mathrm{~F}_{6} \mathrm{~N}_{6} \mathrm{~S}_{2} \mathrm{Ni}$ \\
\hline Formula weight & 553.20 \\
\hline Temperature & $296(2) \mathrm{K}$ \\
\hline Wavelength & $0.71073 \AA$ \\
\hline Crystal system & $I b a 2$ \\
\hline Space group & Orthorhombic \\
\hline & $a=16.889(3) \AA \alpha=90^{\circ}$ \\
\hline Unit cell dimensions & $\begin{array}{c}b=15.777(3) \AA \beta=90^{\circ} \\
c=15.777 \AA \gamma=90^{\circ}\end{array}$ \\
\hline Volume & 4203.7(10) $\AA^{3}$ \\
\hline Z & 8 \\
\hline Density (calculated) & $1.748 \mathrm{Mg} / \mathrm{m}^{3}$ \\
\hline Absorption coefficient & $1.195 \mathrm{~mm}^{-1}$ \\
\hline $\mathrm{F}(000)$ & 2240 \\
\hline Crystal size & $0.35 \times 0.22 \times 0.10 \mathrm{~mm}^{3}$ \\
\hline Theta range for data collection & $\begin{array}{l}2.41 \text { to } 30.15^{\circ} \\
h=-23 \longrightarrow 23\end{array}$ \\
\hline Index ranges & $\begin{aligned} k & =-22 \longrightarrow 18 \\
l & =-21 \longrightarrow 21\end{aligned}$ \\
\hline Reflections collected & 18101 \\
\hline Independent reflections & $5305\left[R_{\mathrm{int}}=0.0691\right]$ \\
\hline Completeness to theta $=30.15^{\circ}$ & $87.0 \%$ \\
\hline Refinement method & Full-matrix least-squares on $\mathrm{F}^{2}$ \\
\hline Data/restraints/parameters & $5305 / 1 / 298$ \\
\hline Goodness-of-fit on $\mathrm{F}^{2}$ & 0.749 \\
\hline Final $R$ indices $[I>2 \operatorname{sigma}(I)]$ & $R_{1}=0.0432, \mathrm{wR}_{2}=0.0652$ \\
\hline$R$ indices (all data) & $R_{1}=0.0934, \mathrm{wR}_{2}=0.0755$ \\
\hline Absolute structure parameter & $-0.006(13)$ \\
\hline Largest diff. peak and hole & 0.394 and -0.231 e..$^{3}$ \\
\hline
\end{tabular}

electron-acceptor character of the complexes which shall lead to the interpretation of the charge transfer process. The lower energy of the HOMO indicates the lower ability as an electrondonor, resulting in higher energy of LUMO and higher resistance to accept electron. This allows elucidation of chemical stability by observing the difference in energy between HOMO and LUMO ( $\left.E_{\text {gap }}\right)$. While large $E_{\text {gap }}$ is preferred for the high stability of complexes with respect to chemical reactions, low $E_{\text {gap }}$ is well sought by the researchers in relating to chemical reactivity in applications such as antibacterial studies due to the ability to encounter efficient charge transfer interactions.

In addition, this study can also explain the chemical concept of chemical softness and hardness. With small $E_{\text {gap }}$, the complexes are considered as "soft" base due to the high energy of HOMO and thus enhance the interaction with the LUMO of soft acids. Other than that, indices such as electron affinity and ionization potential are also commonly interconnected with the studies of HOMO and LUMO energies in pursuing a better grasp of how complexes theoretically behave, chemicalwise.

As can be seen in Figure 5, the electron density of the $\mathrm{NiL}_{2}$ complex is mainly distributed over the nitrogen, sulphur, and $\mathrm{Ni}$ atoms for both HOMO and LUMO. The calculated values of reactivity descriptors parameters are summarized in Table 4. The given low energy gap $(0.460 \mathrm{eV})$ thus indicates high reactivity of the complex due to ease of charge transfer process [24]. The high value of softness (2.174) or the low value of hardness (0.230) indicates lower energy is needed for electron transition from HOMO to LUMO which means that the complex is susceptible to deform and ready to interact with other nucleophilic active site such as amino acid. This is confirmed by the calculation of relatively high value of electrophilic, $\omega(50.233 \mathrm{eV})$ as compared to other work by our group of similar ligand isomer, namely, (Z)-1-[4-(trifluoromethyl)benzylidene]thiosemicarbazide with electrophilic $(\omega)$ value of $1.8073 \mathrm{eV}$ [25].

3.4. Hirshfeld Analysis. Hirshfeld surface analysis has been carried out to illustrate the interactions of the crystal structure and their 2D fingerprint plots were established using CrystaIExplorer3.1 software [26]. The Hirshfeld surfaces for $d_{\text {norm }}$ were obtained and generated as a transparent surface to allow visualization of the molecular structure. The $d_{\text {norm }}(-0.337$ to 1.450) $\AA$ mapping of the Hirshfeld surface (Figure 6) exemplified several red spots in various sizes and intensities. The red spots remarked on the $\mathrm{NiL}_{2}$ complex showed the dominant interactions involving the donor and acceptor. The $\mathrm{C}-\mathrm{H} . \cdots \mathrm{F}$, $\mathrm{N}-\mathrm{H} \cdot \cdots \mathrm{N}$ and $\mathrm{N}-\mathrm{H} \cdots \mathrm{S}$ contacts are present in the studied $\mathrm{NiL}_{2}$ complex. As shown in Figure 6, the interactions at the $\mathrm{NiL}_{2}$ complex backbone between the hydrogen of the amine and its adjacent sulphur atom (N3-H3B...S2) and nitrogen atom (N6-H6C...N2) form a dimeric arrangement in the crystal packing. Also, there is an additional red spot representing the intermolecular hydrogen bonding of the C12-H12A ...F 3 due to the side by side arrangement of the neighbouring complexes in the crystal packing. Besides, from the other side view of the $\mathrm{NiL}_{2}$ complex, the intense red spots revealed the intermolecular hydrogen bonding of N3-H3A...N5 and N6-H6B ...S1 interactions of the $\mathrm{NiL}_{2}$ complex (Figure 6). These two interactions between the adjacent $\mathrm{NiL}_{2}$ complexes are raised due to their dimeric arrangement in the unit cell packing.

The fingerprint plots indicate the percentage contributions of the various intermolecular contacts (Figure 7). In order to highlight all the interactions involved in the crystal packing, each fingerprint plot was divided into the specific pairs of atom-types contributions, such as $\mathrm{H} \cdots \mathrm{F}, \mathrm{H} \cdots \mathrm{H}$, $\mathrm{H} \cdots \mathrm{C}, \mathrm{H} \cdots \mathrm{S}, \mathrm{H} \cdots \mathrm{N}, \mathrm{C} \cdots \mathrm{C}$, and other. The blue coloured represents the assigned reciprocal contacts, while the grey shadow denotes the outline of the original fingerprint plots [27]. $d_{e}$ and $d_{i}$ are the distances from the Hirshfeld surface to the nearest atoms outside and inside the surface [28].

The F...H/H...F contacts appeared as the largest contribution to the Hirshfeld surface (28.5\%). Their two symmetrical narrow spikes of $d_{e}+d_{i} 2.20 \AA$ proved the presence of the intermolecular $\mathrm{C}-\mathrm{H}$...F interactions of the $\mathrm{NiL}_{2}$ complex. Furthermore, the characteristic spikes representing the shortest $\mathrm{H} \cdot \cdots \mathrm{H}$ contacts contributed as the second-largest fingerprint plot to the Hirshfeld surface $(22.2 \%)$ with a high concentration in the middle region as shown in light blue at $d_{e}+d_{\mathrm{i}} 2.25 \AA$. The contribution of the $\mathrm{C} \cdots \mathrm{H} / \mathrm{H} \cdots \mathrm{C}(12.5 \%)$ is indicated by a pair of peaks at $d_{e}+d_{i} 2.80 \AA$. In Addition, the spikes of $\mathrm{S} \cdots \mathrm{H} / \mathrm{H} \cdots \mathrm{S}$ and $\mathrm{N} \cdot \mathrm{H} / \mathrm{H} \cdots \mathrm{N}$ contacts showed $7.4 \%$ and $5.7 \%$ contribution, respectively, which correspond to the presence of $\mathrm{N}-\mathrm{H} \cdots \mathrm{S}$ interactions. The sharpest point in $\mathrm{H}$...S featured a closer contact of $d_{e}+d_{i} 2.60 \AA$, while $d_{e}+d_{i} 2.20 \AA$ for $\mathrm{N}$...H contacts, respectively. Moreover, the $\mathrm{F} \cdot \mathrm{N} / \mathrm{N} / \mathrm{N} \cdot \mathrm{F}$ contacts showed a 
TABLE 2: The experimental and optimized bond lengths $(\AA)$ and angles $\left(^{\circ}\right)$ for $\mathrm{NiL}_{2}$.

\begin{tabular}{|c|c|c|c|c|c|c|c|}
\hline \multicolumn{4}{|c|}{ Bond lengths } & \multicolumn{4}{|c|}{ Bond angles } \\
\hline & Exp. & DFT & Deviation (\%) & & Exp. & DFT & Deviation (\%) \\
\hline Ni1-S2 & $2.175(11)$ & 2.253 & 3.61 & S1-Ni1-N1 & $86.70(10)$ & 85.50 & 1.38 \\
\hline Ni1-N4 & $1.888(3)$ & 1.946 & 3.07 & S2-Ni1-N1 & $96.57(10)$ & 96.00 & 0.59 \\
\hline Ni1-S1 & $2.159(12)$ & 2.253 & 4.36 & Ni1-S1-C9 & $95.78(14)$ & 93.55 & 2.33 \\
\hline Ni1-N1 & $1.892(3)$ & 1.946 & 2.85 & S1-C9-N2 & $123.50(3)$ & 124.7 & 0.97 \\
\hline $\mathrm{S} 2-\mathrm{C} 18$ & $1.722(4)$ & 1.745 & 1.33 & N1-N2-C9 & $112.70(3)$ & 113.7 & 0.89 \\
\hline N4-N5 & $1.371(4)$ & 1.366 & 0.36 & Ni1-N1-N2 & $120.90(2)$ & 120.6 & 0.25 \\
\hline N5-C18 & $1.301(6)$ & 1.311 & 0.76 & S1-Ni1-N4 & $94.56(10)$ & 96.00 & 1.52 \\
\hline N6-C18 & $1.333(5)$ & 1.359 & 1.95 & S2-Ni1-N4 & $84.96(9)$ & 85.50 & 0.64 \\
\hline S1-C9 & $1.717(4)$ & 1.745 & 1.63 & Ni1-S2-C18 & $95.14(13)$ & 93.55 & 1.67 \\
\hline $\mathrm{N} 1-\mathrm{N} 2$ & $1.380(4)$ & 1.366 & 1.01 & S2-C18-N5 & $121.9(3)$ & 124.7 & 2.30 \\
\hline $\mathrm{N} 2-\mathrm{C} 9$ & $1.303(6)$ & 1.311 & 0.61 & N4-N5-C18 & $112.9(3)$ & 113.7 & 0.71 \\
\hline N3-C9 & $1.336(5)$ & 1.359 & 1.72 & Ni1-N4- N5 & $120.1(2)$ & 120.6 & 0.42 \\
\hline
\end{tabular}

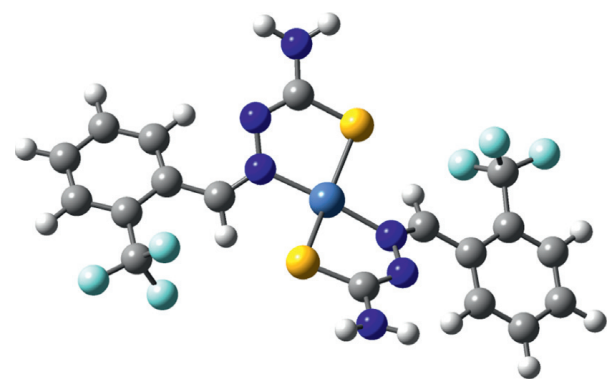

FiguRE 1: Optimized molecular structure of $\mathrm{NiL}_{2}$ complex.

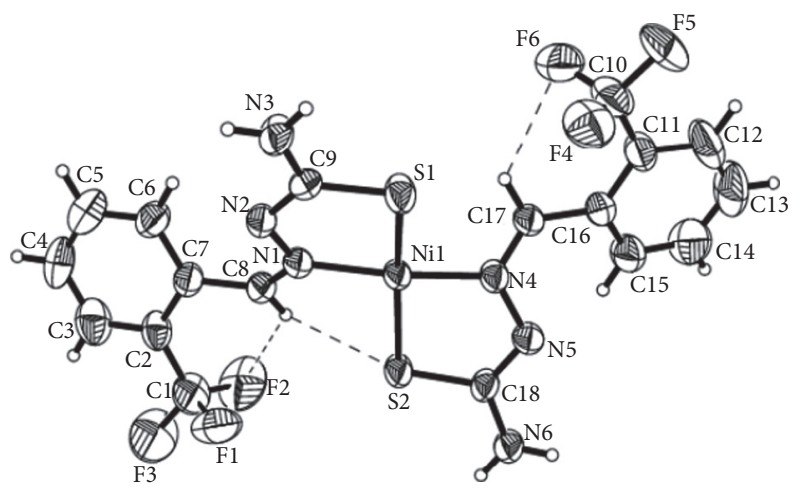

FIGURE 2: Molecular structure of $\mathrm{NiL}_{2}$ complex (50\% probability ellipsoids).

$4.6 \%$ contribution illustrated by a butterfly fingerprint plot with $d_{e}+d_{i} 3.20 \AA$. The C . . C contacts usually refer to $\pi-\pi$ staking interaction [29]. In this $\mathrm{NiL}_{2}$ complex, C...C contacts contributed $3.2 \%$ of the Hirshfeld surface with the sum of $d_{e}$ and $d_{i}$ being approximately $3.5 \AA$. There is also a negligible amount of other contacts contribution $(\mathrm{C} \cdots \mathrm{F}, \mathrm{C} \cdots \mathrm{N}, \mathrm{F} \cdots \mathrm{S}, \mathrm{C} \cdots \mathrm{S}$, and $\mathrm{Ni} \cdot \mathrm{F}$ ), with less than $2 \%$ in the compound. Thus, their contacts are almost insignificant to discuss.

3.5. Molecular Docking. Docking analysis was conducted to investigate the possibility of molecular interaction of $\mathrm{NiL}_{2}$ complex with biologically important proteins. Previous studies have shown the importance of docking analysis for a synthetic compound such as thiosemicarbazide and terphenyl derivatives [30, 31]. Interaction of $\mathrm{NiL}_{2}$ complex with plasma retinol-binding protein 4 (RBP4) (PDB id: 5NU7) was investigated to understand its potency. Physiologically, RBP4 acts as a transporter for retinol [32]. The $\mathrm{NiL}_{2}$ complex docked inside the RBP4 active binding site which is at the same site as the retinol. A total of ten possible $3 \mathrm{D}$ docking orientations of $\mathrm{NiL}_{2}$ complex inside $\mathrm{RB} 4$ active binding site are seen, the highest docking rank with the lowest energy $(\mathrm{kcal} / \mathrm{mol})$ as shown in Figure 8 . Binding affinity is calculated as $-3.3 \mathrm{Kcal} \mathrm{mol}^{-1}$ for $\mathrm{NiL}_{2}$ complex and closer to retinol with $-5.5 \mathrm{Kcal} \mathrm{mol}^{-1}$ (Table 5). According to these results, the most effective intermolecular hydrogen bonds are observed between $\mathrm{NiL}_{2}$ complex through $\mathrm{N}-\mathrm{H}$ atoms and Tyrosine $133(2.05 \AA)$ or Aspartate $102(2.18 \AA)$ in the active binding site (Figure 9). However, the $\mathrm{N}-\mathrm{H}$ intramolecular hydrogen interaction is contrasted with Hirshfeld surface analysis, where F-H interaction is the most dominant $(28.5 \%)$. It is due to the rotation around both $\mathrm{Ni}-\mathrm{N}$ and Ni-S bonds in $\mathrm{NiL}_{2}$ complex for insertion into the RBP4 active site. Similar formations of both antisymmetrical (anti) and symmetrical (syn) isomers of the $\mathrm{Pd}(\mathrm{II})$ and $\mathrm{Pt}(\mathrm{II})$ complexes have been previously reported $[33,34]$. Therefore, the present $\mathrm{NiL}_{2}$ complex has the potential to be a competitive substrate for retinol that is able to bind at the same active binding site of RBP4. Due to the high number of amino acids interacting with the $\mathrm{NiL}_{2}$ complex (via hydrophobic interaction and 
TABLE 3: Hydrogen bonds for $\mathrm{NiL}_{2}$ complex.

\begin{tabular}{|c|c|c|c|c|}
\hline $\mathrm{D}-\mathrm{H}^{\cdots} \mathrm{A}$ & $\mathrm{D}-\mathrm{H}$ & $\mathrm{H}^{\cdots \cdots} \mathrm{A}$ & D*A & $\mathrm{D}-\mathrm{H}^{\cdots} \mathrm{A}$ \\
\hline $\mathrm{C} 8-\mathrm{H} 8 \mathrm{~A} \cdots \mathrm{S} 2$ & 0.93 & 2.52 & $3.125(5)$ & 123 \\
\hline $\mathrm{C} 8-\mathrm{H} 8 \mathrm{~A}^{\cdots} \mathrm{F} 2$ & 0.93 & 2.31 & $2.964(6)$ & 127 \\
\hline C17-H17A $\cdots$ F6 & 0.93 & 2.46 & $3.072(5)$ & 124 \\
\hline $\mathrm{N} 3-\mathrm{H} 3 \mathrm{~B}^{\cdots} \mathrm{S}^{\mathrm{i}}$ & 0.86 & 2.68 & $3.531(3)$ & 170 \\
\hline $\mathrm{N} 3-\mathrm{H} 3 \mathrm{C} \cdot \mathrm{N} 5^{\mathrm{ii}}$ & 0.86 & 2.37 & $3.198(5)$ & 162 \\
\hline N6-H6B $\cdots{ }^{i \mathrm{iii}}$ & 0.86 & 2.76 & $3.622(3)$ & 179 \\
\hline N6-H6C' ${ }^{\cdots} 2^{\text {iv }}$ & 0.86 & 2.41 & $3.188(5)$ & 150 \\
\hline $\mathrm{C} 5-\mathrm{H} 5 \mathrm{~A}^{\cdots} \mathrm{F} 2^{\mathrm{v}}$ & 0.93 & 2.35 & $3.276(6)$ & 175 \\
\hline $\mathrm{C} 12-\mathrm{H} 12 \mathrm{~A}^{\cdots} \mathrm{F}^{\mathrm{vi}}$ & 0.93 & 2.47 & $3.330(7)$ & 155 \\
\hline
\end{tabular}

Symmetry codes: (i) $x, 1-y, 1 / 2+z$; (ii) $1 / 2-x, 1 / 2-y, 1 / 2+z$; (iii) $1 / 2-x, 1 / 2-y,-1 / 2+$; (iv) $x, 1-y,-1 / 2+z$; (v) $1-x, y, 1 / 2+z$; (vi) $x,-1+y, z$.

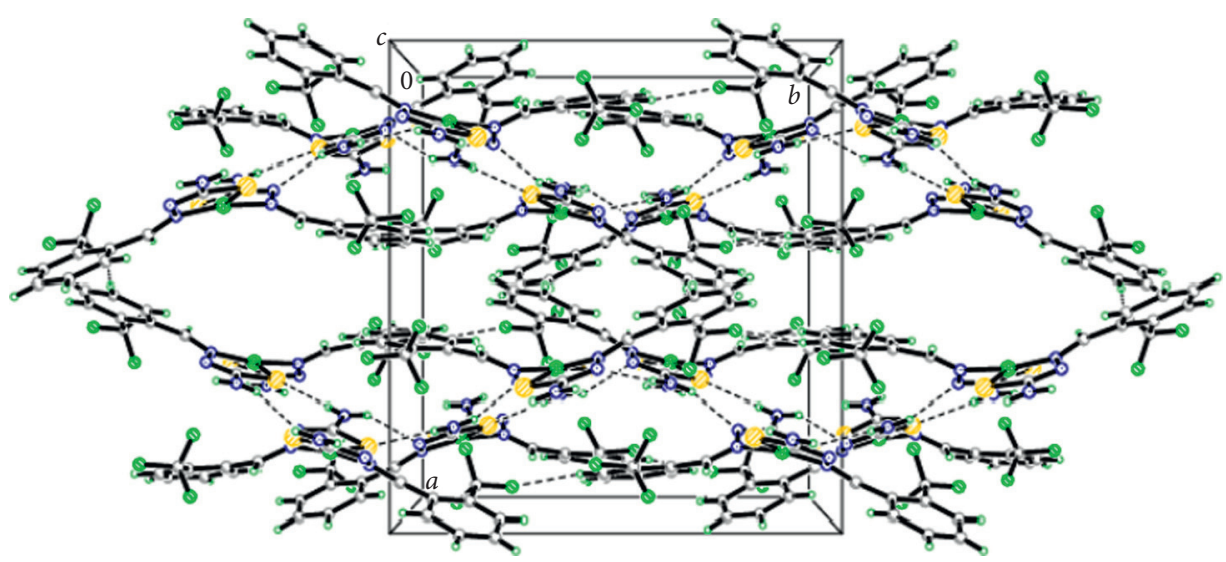

(a)

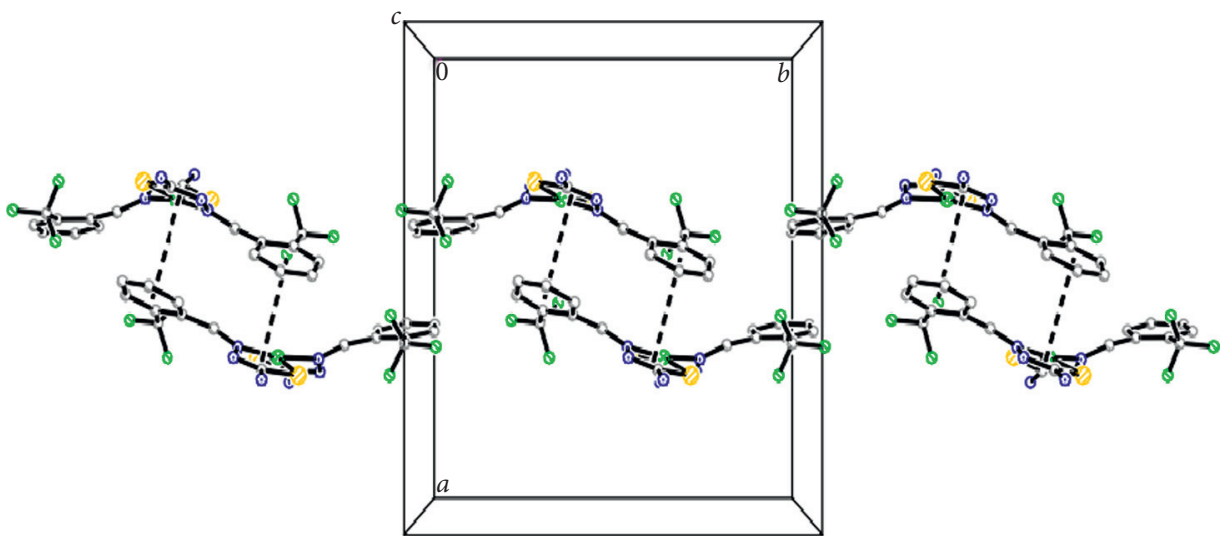

(b)

Figure 3: (a) Molecular packing diagram of NiL2 complex, showing molecules connected by intermolecular hydrogen bonds (dashed lines). (b) $\pi-\pi$ interaction in NiL2 complex. 


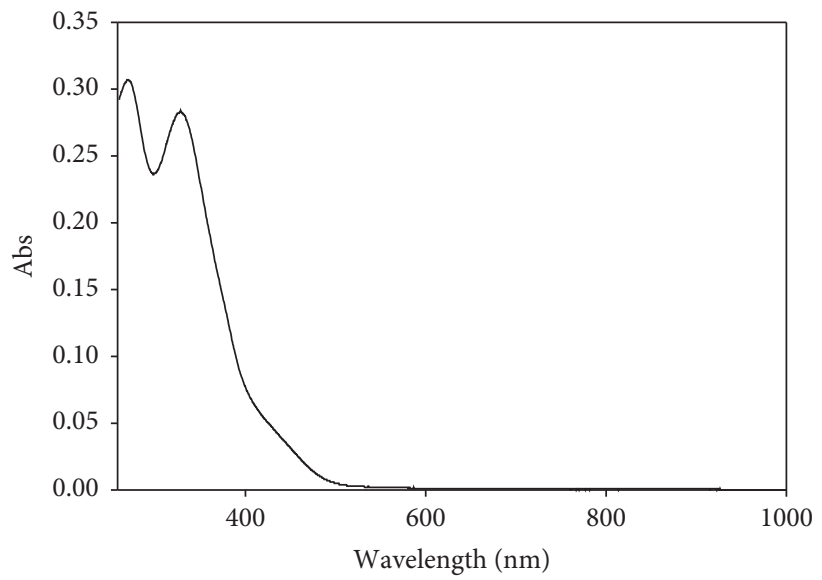

Figure 4: UV-Vis spectrum of $\mathrm{NiL}_{2}$ complex.

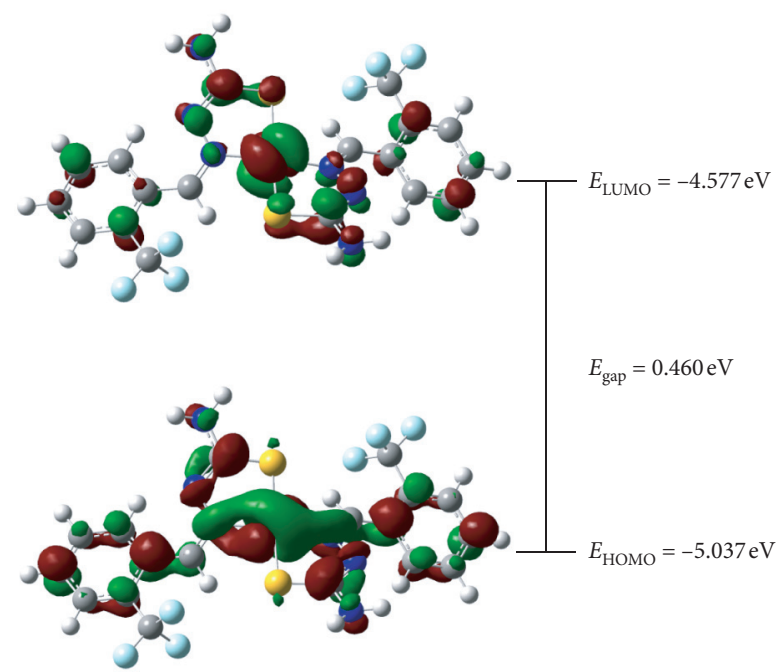

FIgURE 5: HOMO-LUMO surfaces and energy gap for $\mathrm{NiL}_{2}$ complex.

TABLE 4: Reactivity descriptors (in $\mathrm{eV}$ ) of $\mathrm{NiL}_{2}$ complex, computed at B3LYP/LANL2DZ/6-311G $(d, p)$ level of theory.

\section{Parameter}

$E_{\mathrm{HOMO}}$

$E_{\mathrm{LUMO}}$

Energy gap, $\Delta E_{\mathrm{GAP}}=E_{\mathrm{LUMO}}-E_{\mathrm{HOMO}}$

Ionisation potential, $I=-\mathrm{E}_{\mathrm{HOMO}}$

Electron affinity, $\mathrm{A}=-\mathrm{E}_{\mathrm{LUMO}}$

Hardness, $\eta=E_{\mathrm{LUMO}}-E_{\mathrm{HOMO}} 2$

Softness, $S=1 / 2 \eta$

Chemical potential, $\mu=-(\mathrm{I}+A) / 2$

Absolute electronegativity, $\chi=(\mathrm{I}+A) / 2$

$-4.807$

Electrophilicity, $\omega=\chi^{2} / 2 \eta$ 


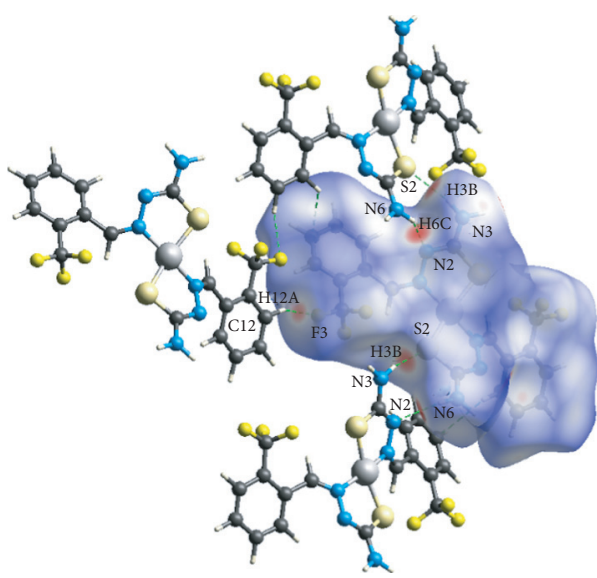

(a)

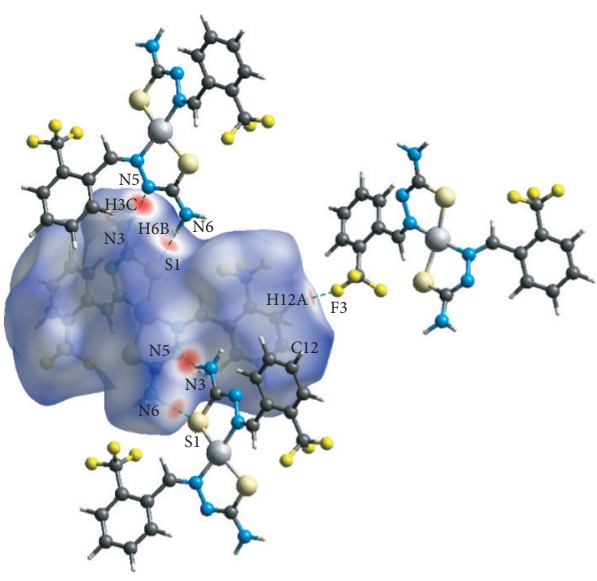

(b)

FIGURE 6: Neighbouring molecules associated with intermolecular hydrogen bonding on a $d_{\text {norm }}$ at the (a) back and (b) front views of NiL $\mathrm{L}_{2}$ complex.
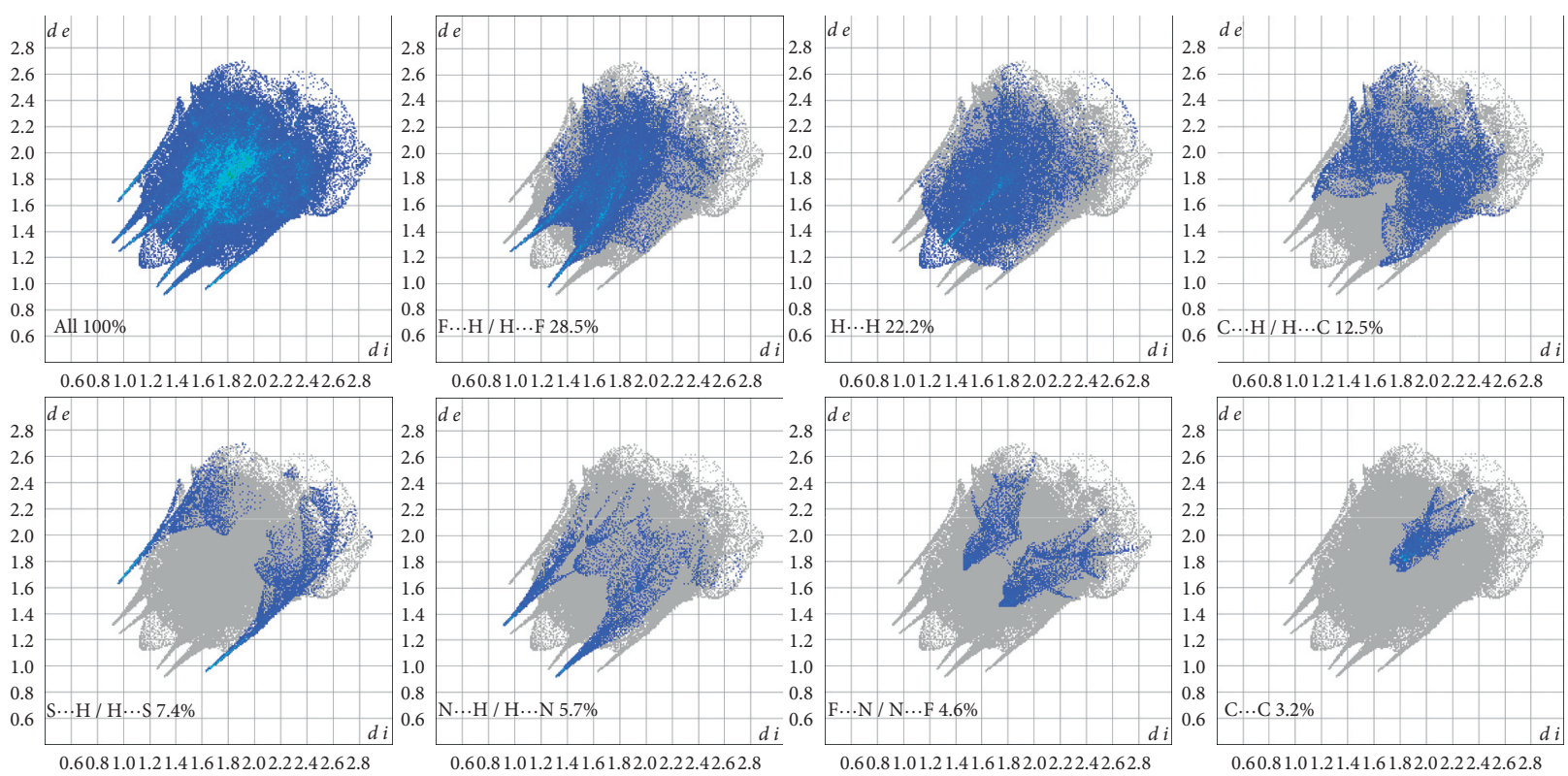

FIGURE 7: Selected fingerprint plots of the intermolecular interactions showing the percentage contributions to the total Hirshfeld surface.

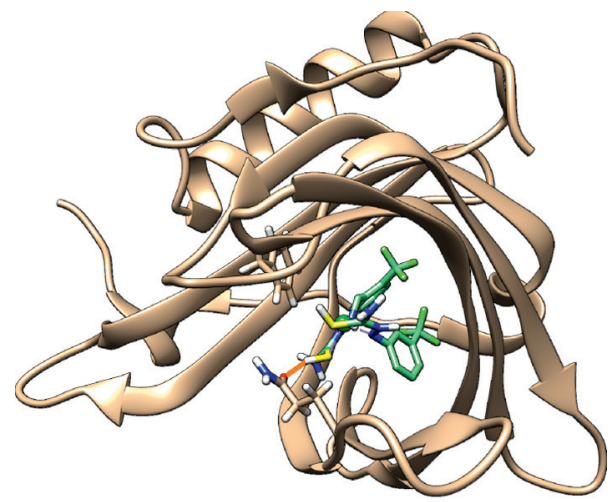

Figure 8: Molecular docking studies of $\mathrm{NiL}_{2}$ complex at the active site of RBP4. 
TABLE 5: Binding affinities $\left(\mathrm{Kcal} \mathrm{mol}^{-1}\right)$ and number hydrogen bonds $\left(H_{\text {bonds }}\right)$ from Autodock analysis of retinol and $\mathrm{NiL}_{2}$ complex.

\begin{tabular}{lcc}
\hline Substrate & Energy $\left(\mathrm{Kcal} \mathrm{mol}^{-1}\right)$ & $H_{\text {bonds }}$ \\
\hline Retinol & -5.5 & 0 \\
$\mathrm{NiL}_{2}$ & -3.3 & 1 \\
\hline
\end{tabular}

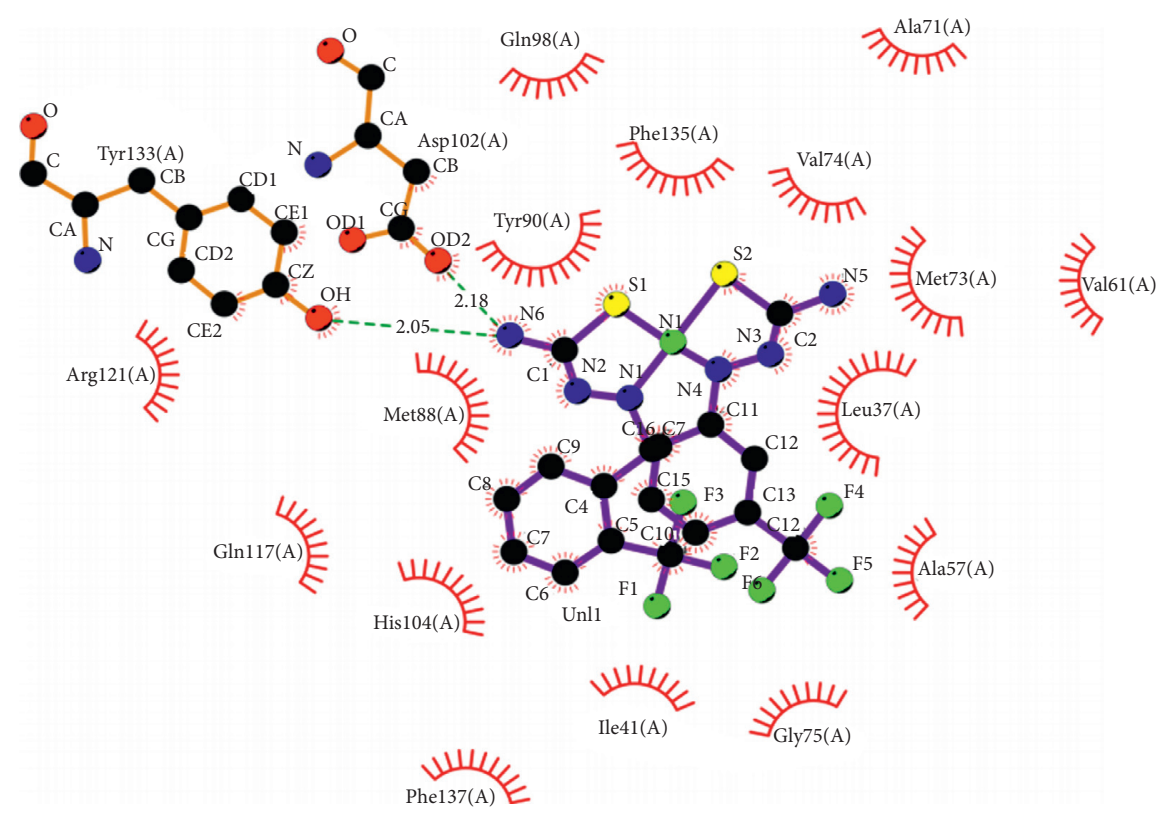

FIgURE 9: Intermolecular hydrogen bonds of $\mathrm{NiL}_{2}$ complex with both Tyrosine 133 and Aspartate 102 at the active site of RBP4.

hydrogen bonds), the release of $\mathrm{NiL}_{2}$ complex from the transporter protein would be slower than the retinol.

\section{Conclusion}

A new complex, bis $\{2-(2$-trifluoromethylbenzylidene)hydrazine-1-carbothioamido- $\kappa^{2} \mathrm{~N}^{2}$, S\}nickel(II), $\left(\mathrm{NiL}_{2}\right)$ was prepared and its structure was characterized by elemental analysis, molar conductance, magnetic susceptibility, and UV-Vis. The structure has been further confirmed by the single X-ray crystallographic which showed a distorted square planar geometry. In addition, the structure of the synthesized $\mathrm{NiL}_{2}$ complex is stabilized by $\pi-\pi$, inter- and intramolecular interactions. The Hirshfeld surface analysis has confirmed the presence of several interactions with $\mathrm{C}-\mathrm{H} \ldots \mathrm{F}$ interactions being the most important features of crystal packing. The paramount findings by the HOMO-LUMO energy gap proven the efficiency of this complex to have charge transfer interactions within the molecule due to the small $E_{\text {gap. }}$. This suggested the facile electrons transfer from the $\mathrm{NiL}_{2}$ donor orbital to the amino acid acceptor, Finally, molecular docking modelling is illustrated between $\mathrm{NiL}_{2}$ complex and plasma retinol-binding protein 4 (RBP4) (PDB id: 5NU7) active site. $\mathrm{NiL}_{2}$ has interacted with both Tyrosine 133 and Aspartate 102 amino acids through $\mathrm{N}-\mathrm{H}$ hydrogen bonds.

\section{Data Availability}

Crystallographic data for the structure reported in this study is deposited at the Cambridge Crystallographic Data Centre under the CCDC no. 2023702. These data can be obtained free of charge via the Cambridge Crystallographic Data Centre, 12 Union Road, Cambridge CB2 1EZ, UK; fax: (+44) 1223-336-033; e-mail through deposit@ccdc.cam.ac.uk.

\section{Conflicts of Interest}

The authors declare that there are no conflicts of interest regarding the publication of this paper.

\section{Acknowledgments}

This work was supported by the Ministry of Higher Education, Malaysia (MOHE), for the financial support in the form of the grant scheme, Fundamental Research Grant Scheme (Ref. FRGS/1/2020/STG05/UMT/02/2) (FRGS-59620). The authors also thank the Faculty of Science and Marine Environment, Universiti Malaysia Terengganu (UMT), for research facilities. The authors gratefully acknowledge the Universiti Sains Malaysia (USM) and Universiti Teknologi Malaysia (UTM) for the technical support.

\section{Supplementary Materials}

Supplementary data include CIF file of the most important compounds described in this article. CCDC no. 2023702 contains supplementary crystallographic data for $\mathrm{NiL}_{2}$. (Supplementary Materials) 


\section{References}

[1] A. D. Khalaji, E. Shahsavani, N. Feizi et al., "Ultrasonic-bathassisted preparation of mononuclear copper(I) thiosemicarbazone complex particles: crystal structure, characterization and antimicrobial activity," Comptes Rendus Chimie, vol. 20, no. 2, pp. 125-131, 2017.

[2] S. Savir, Z. J. Wei, J. W. K. Liew et al., "Synthesis, cytotoxicity and antimalarial activities of thiosemicarbazones and their nickel (II) complexes," Journal of Molecular Structure, vol. 1211, Article ID 128090, 2020.

[3] A. A. Aly, S. Bräse, and P. Weis, "Tridentate and bidentate copper complexes of [2.2] paracyclophanyl-substituted thiosemicarbazones, thiocarbazones, hydrazones and thioureas," Journal of Molecular Structure, vol. 1178, pp. 311-326, 2019.

[4] İ. Babahan, A. Özmen, N. Orhan, D. Kazar, and E. H. Değirmenci, "Synthesis, characterization, and in vitro anti-neoplastic activity of novel vic-dioximes bearing thiosemicarbazone side groups and their mononuclear complexes in vitro anti-neoplastic activity of novel vic-dioximes bearing thiosemicarbazone side groups and their mononuclear complexes," Bioorganic Chemistry, vol. 53, pp. 92-98, 2014.

[5] M. Saswati, M. Mohanty, A. Banerjee et al., "Polynuclear zinc(II) complexes of thiosemicarbazone: synthesis, X-ray structure and biological evaluation," Journal of Inorganic Biochemistry, vol. 203, Article ID 110908, 2020.

[6] N. K. Singh, A. A. Kumbhar, Y. R. Pokharel, and P. N. Yadav, "Anticancer potency of copper(II) complexes of thiosemicarbazones," Journal of Inorganic Biochemistry, vol. 210, Article ID 111134, 2020.

[7] T. Bal-Demirci, Ş. Güveli, S. Yeşilyurt, N. Özdemir, and B. Ülküseven, "Thiosemicarbazone ligand, nickel(II) and ruthenium(II) complexes based on vitamin B6 vitamer: the synthesis, different coordination behaviors and antioxidant activities," Inorganica Chimica Acta, vol. 502, Article ID 119335, 2020.

[8] L. Dkhar, V. Banothu, K. M. Poluri, W. Kaminsky, and M. R. Kollipara, "Platinum group complexes containing salicylaldehyde based thiosemicarbazone ligands: their synthesis, characterization, bonding modes, antibacterial and antioxidant studies," Journal of Organometallic Chemistry, vol. 918, Article ID 121298, 2020.

[9] S. Krishan, D. R. Richardson, and S. Sahni, "The anticancer agent, di-2-pyridylketone 4,4-dimethyl-3-Thiosemicarbazone (Dp44mT), up-regulates the AMPK-Dependent energy homeostasis pathway in cancer cells," Biochimica et Biophysica Acta (BBA)-Molecular Cell Research, vol. 1863, no. 12, pp. 2916-2933, 2016.

[10] U. M. Osman, S. Silvarajoo, K. H. Kamarudin, M. I. M. Tahir, and $\mathrm{H}$. C. Kwong, "Ni(II) complex containing a thiosemicarbazone ligand: synthesis, spectroscopy, single-crystal X-ray crystallographic and conductivity studies," Journal of Molecular Structure, vol. 1223, Article ID 128994, 2021.

[11] U. M. Osman, A. S. N. Farizal, S. Arshad, and M. A. Kadir, "Crystal structure of (Z)-1-[4-(Trifluoromethyl)benzylidene] thiosemicarbazide," X-Ray Structure Analysis Online, vol. 33, pp. 3-4, 2017.

[12] A. Bruker, Saint and SADABS, Bruker AXS Inc., Madison, WI, USA, 2009.

[13] G. M. Sheldrick, "A short history ofSHELX," Acta Crystallographica Section A Foundations of Crystallography, vol. 64, no. 1, pp. 112-122, 2008.
[14] A. L. Spek, "Structure validation in chemical crystallography," Acta Crystallographica Section D Biological Crystallography, vol. 65, no. 2, pp. 148-155, 2009.

[15] D. Sharma, A. Radha, S. Kumar et al., "Synthesis, single crystal $\mathrm{X}$-ray, DFT and HSA of N-donor stabilized complexes of cobalt(II) diphenyldithiophosphate: an experimental and theoretical approach," Journal of Molecular Structure, vol. 1207, Article ID 127835, 2020.

[16] M. N. Wass, L. A. Kelley, and M. J. E. Sternberg, “3DLigandSite: predicting ligand-binding sites using similar structures," Nucleic Acids Research, vol. 38, no. suppl_2, pp. W469-W473, 2010.

[17] E. F. Pettersen, T. D. Goddard, C. C. Huang et al., "UCSF Chimera? A visualization system for exploratory research and analysis," Journal of Computational Chemistry, vol. 25, no. 13, pp. 1605-1612, 2004.

[18] O. Trott and A. J. Olson, "AutoDock Vina: improving the speed and accuracy of docking with a new scoring function, efficient optimization, and multithreading," Journal of Computational Chemistry, vol. 31, no. 2, pp. 455-461, 2010.

[19] R. A. Laskowski and M. B. Swindells, "LigPlot+: multiple ligand-protein interaction diagrams for drug discovery," Journal of Chemical Information and Modeling, vol. 51, no. 10, pp. 2778-2786, 2011.

[20] R. Vasanthakumari, W. Nirmala, S. Sagadevan et al., "Synthesis, growth, crystal structure, vibrational, DFT and HOMO, LUMO analysis on protonated molecule-4-aminopyridinium nicotinate," Journal of Molecular Structure, vol. 1239, Article ID 130449, 2021.

[21] T. K. Venkatachalam, P. V. Bernhardt, G. K. Pierens, and D. C. Reutens, "Synthesis and X-ray crystal structure of 2 and 4-trifluoromethyl substituted phenyl semicarbazone and thiosemicarbazone," Journal of Chemical Crystallography, vol. 47, no. 1-2, pp. 30-39, 2017.

[22] N. M. Metwally and G. A. A. Al-Hazmi, "Spectroscopic evaluation for $\mathrm{VO}(\mathrm{II}), \mathrm{Ni}(\mathrm{II}), \mathrm{Pd}(\mathrm{II})$ and $\mathrm{Cu}(\mathrm{II})$ complexes derived from thiosemicarbazide: a special emphasis on EPR study and DNA cleavage," Spectrochimica Acta Part A. Molecular and Biomolecular Spectroscopy, vol. 107, pp. 289-295, 2013.

[23] T. B. S. A. Ravoof, K. A. Crouse, M. I. M. Tahir, A. R. Cowley, and M. A. Ali, "Synthesis, characterization and bioactivity of mixed-ligand $\mathrm{Cu}(\mathrm{II})$ complexes containing Schiff bases derived from S-benzyldithiocarbazate and saccharinate ligand and the X-ray crystal structure of the copper-saccharinate complex containing S-benzyl- $\beta$-N-(acetylpyrid-2-yl)methylenedithiocarbazate," Polyhedron, vol. 26, no. 6, pp. 1159-1165, 2007.

[24] S. Kumar, A. Radha, M. Kour, R. Kumar, A. Chouaih, and S. K. Pandey, "DFT studies of disubstituted diphenyldithiophosphates of nickel(II): structural and some spectral parameters," Journal of Molecular Structure, vol. 1185, pp. 212-218, 2019.

[25] U. M. Osman, A. S. N. Farizal, M. A. Kadir, M. H. Razali, M. Z. H. Rozaini, and S. Arshad, "Correlation data of (Z)-1[4-(trifluoromethyl)benzylidene] thiosemicarbazide via spectroscopic methods and Density Functional Theory studies," Data in Brief, vol. 27, Article ID 104673, 2019.

[26] S. K. Wolff, D. J. Grimwood, J. J. Mac Kimon, M. J. Turner, D. Jayatilaka, and A. M. Spackman, Crystal Explorer, University of Western Australia, Perth, Australia, 2013.

[27] M. Z. M. Zubir, N. S. Jamaludin, and S. N. A. Halim, "Hirshfeld surface analysis of some new heteroleptic 
Copper(I) complexes," Journal of Molecular Structure, vol. 1193, pp. 141-150, 2019.

[28] A. H. Anizaim, M. F. Zaini, M. A. Laruna, I. A. Razak, and S. Arshad, "(E)-1-(Benzo[d][1,3]dioxol-5-yl)-3-([2,2'-bithiophen]-5-yl)prop-2-en-1-one: crystal structure, UV-Vis analysis and theoretical studies of a new $\pi$-conjugated chalcone," Acta Crystallographica Section E Crystallographic Communications, vol. 75, no. 5, pp. 632-637, 2019.

[29] N. H. H. Hassan, A. A. Abdullah, S. Arshad, N. C. Khalib, and I. A. Razak, "Crystal structure and Hirshfeld surface analysis of (E)-3-(2-chloro-6-fluorophenyl)-1-(3-fluoro-4-methoxyphenyl)prop-2-en-1-one," Acta Crystallographica Section E Crystallographic Communications, vol. 72, no. 5, pp. 716-719, 2016.

[30] U. M. Osman, K. H. Ku Bulat, M. H. Razali, M. F. N. Hassim, F. A. Fauzi, and Y. Juahir, "Synthesis, DFT computational studies and biomolecular interactions of 4-(2-fluorophenyl) thiosemicarbazide," ASM Science Journal, Special Issue, vol. 2018, no. 1, pp. 147-157, 2018.

[31] F. A. Fauzi, M. S. Goh, S. A. T. T. Johari, F. Hashim, and M. F. N. Hassim, "Dream over life: psychedelic terphenyl derivative induce hallucination via cannabinoid receptor 1 ," IOP Conference Series: Materials Science and Engineering, vol. 440, no. 1, p. 012045, 2018.

[32] M. Perduca, S. Nicolis, B. Mannucci, M. Galliano, and H. L. Monaco, "Human plasma retinol-binding protein (RBP4) is also a fatty acid-binding protein," Biochimica et Biophysica Acta (BBA)-Molecular and Cell Biology of Lipids, vol. 1863, no. 4, pp. 458-466, 2018.

[33] V. Montoya, J. Pons, X. Solans, M. Font-bardia, and J. Ros, "Synthesis, spectroscopic properties and structural characterisation of $\mathrm{Pd}(\mathrm{II})$ and $\mathrm{Pt}(\mathrm{II})$ complexes with 1,3,5-pyrazole derived ligands. Rotation around the metal-N bond," Inorganica Chimica Acta, vol. 358, no. 7, pp. 2312-2318, 2005.

[34] G. Natile, F. Gasparrini, D. Misiti, and G. Perego, "Hindered rotation about the metal-nitrogen bond in trans-dichlorodihydrazonepalladium(II) complexes and X-ray crystal structure of trans-bis(acetone methylphenylhydrazone) dichloropalladium(II)," Journal of Chemical Society, Dalton Transactions, vol. 18, no. 18, pp. 1747-1752, 1977. 